\title{
Teatro, ciência e divulgação científica para uma educação sensivel e plural
}

\section{Theater, science and science communication for a sensitive and plural education}

Thelma Lopes ${ }^{1}$

Mônica Santos Dahmouche ${ }^{2}$ 


\section{Resumo}

O momento em que vivemos tem sido marcado por profundos retrocessos em vários campos da atuação humana e em diferentes partes do globo, especialmente na América Latina. Em tempos nos quais direitos básicos são ignorados, as artes, erroneamente, são vistas como supérfluas e atacadas frontalmente. A despeito do cenário desfavorável, há iniciativas que se fortalecem na busca de ambientes alternativos aos espaços tradicionais de criação artística e no diálogo colaborativo entre múltiplas áreas do conhecimento. O principal objetivo deste artigo é estimular a discussão acerca do intercâmbio entre teatro, ciência e cidadania, tendo como pano de fundo as ações desenvolvidas no Museu Ciência e Vida.

Palavras-chave: Teatro e ciência; educação sensível; teatro e cidadania; teatro e divulgação científica

\section{Abstract}

The moment in which we live has been marked by deep setbacks in various areas of human activity and in different parts of the globe, especially in Latin America. In times when basic rights are ignored, the arts are considered superfluous and frontally attacked. Despite the unfavorable scenario, there are initiatives that search for alternative environments to the traditional spaces of artistic creation and in the collaborative dialogue between multiple areas of knowledge. The main objective of this article is to stimulate discussion about the exchange between theater, science and citizenship, related with the actions developed at the Museu Ciência e Vida.

Keywords: Theater and science; sensitive education; theater and citizenship; theater and science communication

E-ISSN: 2358.6958

\footnotetext{
1 Mestre em Teatro e doutora em Ciências. Servidora da Fundação Cecierj. tgardair@cecierj.edu.br

1 Profa. Dra. Fundação Cecierj, atualmente ocupa o cargo de vice-presidente científica da instituição. Integrante do "Observatório de Museus e Centros de Ciência e Tecnologia". monicacecierj@gmail.com
} 


\section{Arte, ciência e sociedade}

Nas sociedades modernas, especialmente em áreas mais pobres, em situação de fragilidade social, onde as condições mínimas de conforto econômico e dignidade social não são atendidas, as artes costumam ser vistas como supérfluas e dispensáveis quando comparada às necessidades consideradas básicas do ser humano. São apreciadas, mas não, necessariamente, compreendidas como vitais. Por vezes são encaradas como um luxo a ser gerado e usufruído por poucos eleitos. As ciências, por sua vez, principalmente quando associadas à produção tecnológica, são tidas como imprescindíveis. Aplicações práticas de estudos científicos no campo da saúde, por exemplo, contribuem, decisivamente, para reforçar o caráter essencial das ciências uma vez que evidenciam funções ligadas à manutenção da vida.

Contudo, é preciso observar que a despeito dos distintos status conferidos às artes e ciências, e do fato de que alguns saberes venham sendo valorizados em detrimento de outros, vivemos, no Brasil, em meio a um cenário de desapreço à produção de conhecimento como um todo. Em pleno século XXI, na área das ciências mais consagradas, por exemplo, não têm faltado críticas infundadas à esfericidade do planeta ou às pesquisas de nomes como Charles Darwin. Estudos que envolvem destacadamente a reflexão, fruição, aguçamento estético ou formulação de conceitos, também vêm sendo depreciados, seja em discursos ou ações concretas. Recentemente, disciplinas como Sociologia ou Filosofia sofreram redução na carga horária obrigatória, tendo sido cogitado a exclusão das mesmas do currículo escolar.

Entre compreensões equivocadas e estereotipadas, há muitas nuances e deformações a serem observadas, corrigidas e que devem ser postas em relação a múltiplos variantes. Não se trata de tarefa simples. Exige consciência da complexidade que envolve a interação dos temas relacionados na discussão proposta, e sensibilidade para identificar os meandros por entre os quais artes e ciências estabelecem pontos de contato ou afastamento, sejam eles ditados por razões históricas, metodológicas, circunstanciais, sociais ou políticas, ou, ainda, pela conjunção simultânea de tais pontos. Nesse sentido, Lopes observa:

Arte e Ciência, hoje, podem parecer duas áreas distantes e antagônicas, mas a relação entre as duas, que se subdividem em outras, nem sempre foi de distância. Pintores renascentistas aplicavam princípios matemáticos para conferir ilusão de volume e proporção às imagens, visando retratar a natureza realisticamente. Os médicos, por sua vez, recorriam aos artistas, que, ao registrarem dissecações, como Rembrandt, em "Lição de anatomia", documentavam o corpo humano gerando fontes de estudo inéditas. Já Escher utilizou a geometria para criar realidade à parte: infinita e fantasiosa. Quando o paradigma dominante passou a ser o científico, Arte e Ciência foram afastadas, especializando métodos, processos e linguagens. Um vocabulário relacionado à Ciência foi incorporado ao cotidiano, por diferentes setores da sociedade, de forma indiscriminada, por vezes deturpada, e outras com fins mercadológicos. O caráter utilitário da Ciência e a concretude do progresso tecnológico contribuíram para que a última passasse a ser encarada como algo inconteste. Como duvidar do "cientificamente comprovado"? Não se trata de dispensar ou banalizar a Ciência, o que por si só seria uma ingenuidade nos dias atuais, face ao consenso generalizado de sua autoridade no âmbito social, a despeito das críticas a tal status dentro da própria Ciência e dos recentes retrocessos (Lopes, 2018, p.9). 
Bruno Latour é um dos críticos importantes da hegemonia das ciências. Para ele, "essa Ciência com C maiúsculo não é uma descrição do que os cientistas fazem [...] é uma ideologia que nunca teve qualquer outro uso nas mãos do epistemologista, senão o de oferecer um substituto para a discussão pública" (Latour, 2001, p. 148). O autor defende que não há uma ciência pura, desvinculada das práticas e interesses políticos e que como tal, ciência alguma pode ser absolutizada. Contudo, se por um lado há supremacia do saber científico, por outro, grande parte da população não especializada relaciona a prática das ciências a assuntos complexos e, em tese, distantes de sua capacidade de compreensão. Tem sido comum que o público leigo não se sinta à vontade ou mesmo apto para questionar o que é posto como verdade indiscutível. Dessa forma, tornou-se recorrente o entendimento errôneo de que as ciências seriam algo de exclusivo interesse e domínio de cientistas. A noção de que as consequências dos atos, decisões e estudos desenvolvidos pelos pesquisadores incidem não apenas sobre eles próprios, mas repercutem na sociedade irrestritamente, é algo a ser construído e consolidado.

A consciência de que embora as repercussões das produções científicas atinjam a vida de todos, e que, todavia, seus benefícios não são igualmente disponibilizados para as várias camadas da população, também precisa ser instituída, pois é condição fundamental para transformar tal deformação. "Os leigos podem e devem supervisionar a Ciência" (Feyerabend, 2011, p. 120). Fato é que, de maneira geral, por razões distintas, artes e ciências parecem apartadas da vida cotidiana, e assim não devem permanecer, pois, neste caso, o afastamento contribui para alimentar as desigualdades. Nesse cenário, as ações de divulgação científica, em particular aquelas que promovem diálogo com outras áreas do conhecimento, ocupam papel central porque visam à apropriação e democratização dos saberes. Cabe destacar a polissemia do termo:

\footnotetext{
"Divulgação científica" é uma expressão que designa atualmente a transmissão de conhecimento científico para um público leigo no assunto; como acréscimo deveríamos considerar que a divulgação entre os pesquisadores também é científica. Como prática social, pode apresentar objetivos variados e é tão ampla que não se pode abarcá-la toda de uma vez. Inclui iniciativas como a publicação do livro A evolução da Física [...]; a criação do canal de TV Discovery Channel, em 1985; o lançamento da revista Superinteressante, em 1987 ou da enciclopédia Conhecer, em 1966; a publicação em 1982 da revista Ciência Hoje (Massola, Crochik, Svartman, 2015, p.310).
}

As iniciativas de divulgação científica se apresentam em diferentes modalidades e envolvem veículos e atores sociais diversos, como podemos confirmar nas palavras supratranscritas. No campo da interação entre arte e ciência, destaca-se o manifesto "ArtScience" (Root-Bernstein, Siler, Brown, Snelson, 2011, p.192) no periódico Leonardo. O documento é uma defesa categórica da aglutinação entre arte e ciência criando um campo único e inovador. Daí a proposta do termo ArtSience, no qual as duas palavras de origem se fundem em uma, rompendo as barreiras disciplinares entre elas.

A ideia de comunicar a ciência de forma ampla está presente no percurso de cientistas célebres como Galileu Galilei que já no século XVI, época na qual a língua 
oficial das obras e documentos respeitáveis era o latim, tanto no que se refere às produções nos campos da arte ou da ciência, escreveu em diálogos e em italiano.

\footnotetext{
Não se trata de romantizar a imagem deste cientista, mesmo porque a opção pelo idioma italiano não deve ter sido regida, apenas, por motivos altruístas ou democráticos, mas não podemos deixar de considerar que esta iniciativa de Galileu foi fundamental para socializar, em alguma medida, uma parcela importante da produção científica da época (Gardair, 2012, p.320).
}

Um dos mais populares cientistas da atualidade, Albert Einstein, publicou com LeopoldInfel, em 1938, o livro A evolução da Física, cujo objetivo era divulgar os principais preceitos da teoria da relatividade junto ao público não especializado. No Brasil, o surgimento da divulgação científica está vinculado, especialmente, à institucionalização e profissionalização das ciências, bem como à validação das mesmas junto à sociedade. É hoje uma área reconhecida pelas agências de fomento e consta em plataformas oficiais como área do conhecimento.

A conceituação terminológica é ainda objeto de discussão. Vulgarização, jornalismo científico e popularização da ciência são alguns dos termos utilizados para caracterizar objetivos e motivações das ações de divulgação científica que, de maneira genérica, podem ser compreendidas como iniciativas que visam apresentar conteúdos de forma mais palatável ao público leigo e encorajar a crítica em relação ao exercício das ciências.

Assim sendo, considerando a atual conjuntura, as atividades de divulgação tornam-se ainda mais cruciais, pois buscam o diálogo com a coletividade social. Isto porque, ainda que vivamos tempos de combate ao conhecimento, momento em que a mediocridade e o obscurantismo vêm sendo consagrados em tantos âmbitos, principalmente por parte daqueles que minimizam a importância da educação ampla e irrestrita, há que se voltar os olhos, também, para o lapso criado pelos próprios cientistas e artistas entre suas produções e a sociedade. Muitas vezes a linguagem hermética, a erudição excessiva, o desprezo às culturas locais, ou a despreocupação em estabelecer comunicação que alcance além dos pares ou iniciados, compromete o interesse do púbico leigo. Nessa perspectiva, é importante ressaltar alguns dos desafios a serem enfrentados: como ser acessível e simples, sem ser simplório ao redigir artigos científicos ou ao criar uma obra de arte?

Trata-se de tarefa tão complexa quanto imprescindível. Complexa porque para compreender determinadas proposições é preciso o domínio de concepções prévias e alfabetos específicos que nem sempre são passíveis de ampla tradução para o público não especializado. Imprescindível porque para que este público veja sentido na existência das instituições educativas e promotoras de conhecimento artístico e científico, é necessário que se construam relações de pertencimento com tais instituições. Para tanto, o conhecimento não pode estar confinado nas universidades e espaços oficiais de cultura, de arte ou acadêmicos. É fundamental o estreitamento dos laços por meio da elaboração de formas de comunicação mais amigáveis.

Esforços em diferentes âmbitos vêm sendo empreendidos. Ações de divulgação cientifica em espaços, e veículos, de educação não formal, tais como museus, centros itinerantes, publicações, vídeos, podcasts, dentre outros, têm se incumbido 
de difundir conteúdos, temas e controvérsias das ciências. Práticas teatrais, por sua vez, ao extrapolarem os palcos e ocuparem locais não convencionais, dentre os quais se incluem presídios, comunidades, hospitais ou organizações não governamentais, tendem a favorecer a aproximação de diferentes públicos proporcionando a familiarização com múltiplas artes e suas respectivas linguagens. Sobre este aspecto, no campo do teatro, Coutinho esclarece:

[...] uma grande diversidade de práticas teatrais cruza a fronteira das salas convencionais do teatro para alcançar e agir em outras esferas: como em projetos comunitários realizados nas periferias e favelas das grandes cidades; em ações na área da educação não formal, fora dos muros das escolas; nos hospitais, nas prisões; em ações patrocinadas por empresas ou nos projetos das organizações não governamentais. (Coutinho, 2012, p.111)

Ao vivenciar diferentes etapas e locus do processo teatral, podendo ocupar a plateia ou os palcos (cada vez mais numerosos e plurais) o público vê suas possibilidades de apropriação da linguagem teatral ampliadas. Há muito a ser explorado e múltiplas estratégias possíveis. Enfocaremos aqui o intercâmbio entre teatro e ciência, no âmbito da divulgação científica, em prol da democratização dos saberes e de promoção de processos educativos sensíveis e plurais.

\section{Teatro, Ciência ${ }^{3}$ e divulgação científica}

Quando olhamos particularmente o caso da ciência e do teatro, vemosuma longa trajetória, sobretudo de encontros, que também se iniciana Grécia Antiga, com o teatro grego, especialmente com a tragédia,e seus questionamentos sobre conhecimento e poder. Nessa vertente,destaca-se Prometeu acorrentado, peça de Ésquilo inspirada no mitodo Prometeu, que trata do castigo dado por Zeus, divindade suprema, ao titã Prometeu, por este ter roubado o fogo, que pertencia aos deuses, e o entregado aos humanos, desprezados pelo Olimpo. Ocupando-se de temas como transgressão, luta pela liberdade e domínio doconhecimento e da técnica, a obra surge em um período em que aciência e a arte possuíam laços fortes e indissociáveis (Almeida, Lopes, 2019, p.29).

Da Grécia à contemporaneidade, ao se pensar na interação entre teatro e ciência, observamos que:

[...] três peças emblemáticas não podem deixar de ser citadas: Vida de Galileu (1956), de Bertolt Brecht, Os Físicos (1960), de Friedrich Dürremant e O Caso Oppenheimer (1964), de HeinarKipphardt. Os textos giram em torno da repercussão da bomba atômica e da nova responsabilidade do cientista diante da sociedade. As peças exploram o dilema da relação entre técnica e ética, simbolizada na energia nuclear e seus potenciais de criação e destruição. (...) Em Vida de Galileu, Brecht nos apresenta um Galileu que nega seus novos conhecimentos diante das pressões da cúria italiana, propondo reflexão sobre o cientista que se deixa intimidar pelo poder estabelecido". (Gardair, 2012, p.26)

A história do cientista italiano é tema recorrente na obra Brechtiana, durante, pelo menos, 18 anos de sua obra dramatúrgica e teórica escreveu três versões principais

\footnotetext{
3 A discussão mais aprofundada sobre relações entre teatro e ciência foi explorada na tese intitulada: "Integrando a percepção de estudantes à criação de peça teatral: uma alternativa de educação científica em diálogo com as artes", listada nas referências ao fim deste artigo.
} 
sobre a vida de Galileu. A primeira em 1938-39, na Dinamarca, a segunda em 1946-47 nos Estados Unidos e a terceira em 1953-56 na Alemanha. Precedendo a versão dinamarquesa, numerosas notas inéditas e esquetes que sugerem formulação diferente das outras três. Em Os Físicos, Dürremant leva à cena a responsabilidade do cientista diante de suas descobertas. O autor "explora o que considera contradições inerentes ao conhecimento especializado e questiona a atuação de cientistas que detinham o saber que poderia vir a significar o extermínio da humanidade" (Gardair, 2012, p.26). Indo ao encontro dos princípios da prática documental, típica dos anos 1960, que utilizava como fonte de inspiração e base, reportagens jornalísticas, Kipphardt concebe O Caso Oppenheimer. Fundamentando-se em documentos de processo homônimo, referente ao caso verídico no qual o físico J. Robert Oppenheimer foi julgado, o autor propôs a reflexão sobre os interesses estatais e o ofício do cientista.

As três peças conectaram-se a uma época na qual questões cruciais estavam sendo polemizadas e colocavam as ciências em xeque, contribuindo, assim, para transformar a ética científica em tema dramatúrgico. A eclosão da bomba atômica em Hiroshima e Nagasaki e suas traumáticas repercussões, as acusações públicas a J. Robert Oppenheimer, "os intentos do governo de Konrad Adenauer para equipar seu exército com armamento nuclear, a guerra do Vietnam e o movimento estudantil de 1968" (Gardair, 2012, p.26), são algumas das questões latentes do período.

"A Estátua Amazônica, de Araújo Porto Alegre (1851) Lição de Botânica (1906), (...) de Machado de Assis, Copenhagen (1998), de Michael Frayn, ou A Prova (2000), peça escrita por David Auburn" (Gardair, 2012, p.27), são exemplos de textos, de estilos, momentos históricos e gêneros variados, que abordam temas relacionados à prática científica. E não têm sido poucas as temporadas com peças que exploram o mundo das ciências.

No Brasil, por exemplo, podemos citar pelo menos meia dúzia de produções recentes que abordam questões relacionadas à ciência: A máquina de abraçar, de José Sanches Sinisterra, com direção de Malu Galli; A prova, de David Auburn, com direção de Aderbal Freire-Filho; A tartaruga de Darwin, de Juan Mayorga, com direção de Mika Lins; [...]; Cérebro-coração, de Mariana Lima, com direção de Renato Linhares e Enrique Diaz; e a peça infantil Isaacno mundo das partículas, adaptação do livro de Elika Takimoto, com direção de Joana Lebreiro. (Almeida, Lopes, 2019, p.32)

Cabe ressaltar também publicações brasileiras que compilam textos teatrais voltados para a discussão de múltiplas ciências, tais como Aids e teatro: 15 dramaturgias de prevenção ${ }^{4}$ e Histórias do Brasil para teatro ${ }^{5}$. Contudo, se a ciência como tema do teatro deve ser destacada, e, em certa medida, pode ser considerada fenômeno relativamente recente, é importante refletir sobre possíveis especificidades, que extrapolam a questão da ciência como temática em si, e que justificariam a associação entre educação científica e linguagem teatral. Como observa Flávio Desgranges, Brecht é "figura-chave nas reflexões traçadas entre teatro e educação" (Desgranges, 2010, p. 31). É possível verificar no conjunto da obra teórica e dramatúrgica do artista alemão seu interesse pelo avizinhamento com as Ciências.

4 Daniel Souza; Marta Porto (Org.), 2004.

5 Antonio Bivar; Celso L.Paulini, 2007.

Thelma Lopes, 
Brecht não apenas explorou as ciências como tema, mas foi além ao buscar incorporar elementos da metodologia científica em seu método teatral. Em seus escritos, ele ressalta, por exemplo, a importância da observação associada à experimentação, tal qual no método Galileano. (Gardair, 2012, p.27)

Para Brecht o ato de observar constitui papel fundamental no processo de representação desenvolvido pelos atores. Nesse sentido, é importante salientar que segundo a concepção do dramaturgo, a observação não pode ser reduzida a um mero ato contemplativo. Ao contrário, trata-se de atitude crítica, em interação com o mundo ao redor e estado permanente de vigilância ao próprio corpo, encarando-o como potente e múltiplo instrumento de comunicação e expressão. "O ator observa o seu próximo, com todos os seus músculos e nervos" (Brecht, 1978, p. 121) corporificando e relativizando o que observa.

Galileu foi um dos primeiros a preconizar a ciência experimental, ou seja, a incorporar à metodologia científica, mecanismos de testagem, não se limitando à observação pura e simples. Aqui há importante ponto de contato com o teatro de Brecht: uma oposição comum a Aristóteles.

Brecht, quando formulou a teoria do teatro épico, buscava a contaminação de gêneros que tradicionalmente eram considerados mutuamente excludentes. $\mathrm{Na}$ verdade, o conceito brechtiano de teatro aristotélico abrangia todo tipo de teatro em que prevalecesse a identificação na relação palco-plateia (Lopes, 2000, p.15).

A ciência de Aristóteles apresenta uma "verdade científica" pronta e acabada, sem submetê-la a checagem. O que é observado não é testado. Diferentemente, a ciência de Galileu expõe o processo por meio do qual se alcançou uma conclusão científica, possibilitando a exposição de eventuais erros advindos de suposições preliminares. Assim como Galileu em sua prática científica, Brecht buscou imprimir um caráter experimental ao seu teatro. Vejamos:

\footnotetext{
A produção bem feita é aquela cujas marcas dos ensaios foram removidas(exatamente como na mercadoria reificada em que os traços da produção foram eliminados): Brecht abre esta superfície e permite-nos recuar aos gestos alternativos e às posturas dos atores ensaiando seus papéis; assim é que é a experimentação estética - que costuma ser entendida como geradora do novo e do ainda não experimentado - poderia muito bem ser entendida como a tentativa "experimental" de excluir a reificação. (Jameson, 1999, p. 29-30)
}

"Se a época de Galileu, o cientista que mais inspirou o dramaturgo, foi o período de afirmação das ciências naturais, Brecht considerou que o século XX afirmaria o domínio das ciências humanas" (Lopes, 2003, p. 178-179). Dentre estas, principalmente a economia e a sociologia. Se as ciências naturais tiveram como objeto de estudo a natureza, as ciências sociais investigariam a organização da sociedade, matéria-prima do teatro Brechtiano. O dramaturgo considerava que,apesar dos objetos distintos, ambas as ciências transformariam radicalmente os âmbitos científico e social.

De fato, o desenvolvimento das ciências naturais, liderado por Galileu, deflagrou a primeira revolução científica, promovendo nova forma de controle da natureza, tendo sido conduzida pela classe ascendente de então, a burguesia. Os estudos 
de Galileu consolidaram a chamada primeira revolução científica, que é considerada pelos historiadores:

[...] como uma das mais profundas, senão a mais profunda revolução do pensamento humano desde a descoberta do Cosmo pelo pensamento grego, revolução que implica uma radical mutação intelectual da qual a ciência física moderna é ao mesmo tempo fruto e expressão. (Koyré, 1991, p. 153)

Para Brecht, a segunda revolução científica ocorreria no século XX, a partir das ciências humanas. A transformação se daria no campo das relações dos homens em sociedade, e também seria conduzida por uma classe social, desta vez, o proletariado. O dramaturgo manteve o diálogo com Galileu ao longo de toda sua vida, seja elaborando as diferentes versões da peça sobre o cientista, seja concebendo A Compra do Latão, obra declaradamente inspirada no livro de Galileu Diálogo concernente aos dois principais sistemas do mundo. No campo da divulgação científica especificamente identificamos um crescente interesse por iniciativas que mesclam teatro e ciência de múltiplas maneiras.

Uma quantidade expressiva dessas iniciativas tem ganhado visibilidade por meio das redes e dos eventos que reúnem a comunidade de profissionais e pesquisadores da área, tais como a Rede de Popularização da Ciência e da Tecnologia na América Latina e no Caribe (RedPop), a Rede Europeia de Centros de Ciência e Museus (Ecsite) e a Rede de Comunicação Pública da Ciência e da Tecnologia (PCST). Apesar de alguns países, como o Reino Unido e os Estados Unidos, se destacarem mais que outros nessa seara, há registros de iniciativas de divulgação científica unindo ciência e teatro em várias partes do mundo, incluindo Nova Zelândia, Quênia, Nepal, Camboja, Tailândia, Vietnã, Índia, Holanda, Grécia, Itália, Portugal, Espanha, Argentina, Peru e Brasil. (Almeida, Lopes, 2019, p. 33)

Em levantamento sobre ações explorando artes cênicas realizadas em Museus e Centros de Ciência, no Brasil, verificou-se "14 instituições que sinalizaram positivamente quanto à presença dessas ações" (Moreira, Marandino, 2015, p.1741). Cabe destacar que a natureza das experiências em curso é múltipla e inclui desde esquetes curtos até peças de teatro, que cumprem temporada regular, nas quais estão envolvidos artistas e técnicos de espetáculos profissionais. É possível, também, verificar o desenvolvimento de visitas teatralizadas a exposições com temas científicos, apresentações circenses e os chamados "shows de ciência", que costumam apresentar números de pirotecnia e pequenas explosões, com o intuito de atrair a audiência por meio de espetacularização.

\section{Ciência e Teatro no Museu Ciência e Vida: desafios e resultados}

O Museu Ciência e Vida $(\mathrm{MCV})$ é um centro interativo de divulgação científica localizado em Duque de Caxias, área da baixada fluminense com um dos menores índices de desenvolvimento humano do país. "É fruto de uma política pública voltada às necessidades locais, tendo sido pensado e planejado para suprir parte da falta de

6 O MCV está vinculado ao setor de divulgação científica da Fundação Centro de Ciências e Educação Superior a Distância do Estado do Rio de Janeiro, Cecierj, Secretaria de Ciência Tecnologia e Inovação do Estado do Rio de janeiro, tendo contado com o apoio da Fundação de Amparo à Pesquisa do Estado do Rio de Janeiro, Faperj. 
oferta cultural na região" (Almeida et alli, 2018, p.379). A instalação e manutenção de um museu nesta área estão, antes de tudo, ligadas à prática cidadã, haja vista que no Brasil os equipamentos culturais estão distribuídos de forma desequilibrada concentrando-se nas áreas nobres das cidades. Destaca-se que nesta conjuntura não bastaria inaugurar o espaço físico sem a idealização de uma programação de atividades que contribuísse para a construção de relações de pertencimento entre a população e o MCV.

Os estudos realizados para o planejamento das atividades apontaram que a parceria com instituições consagradas, e, principalmente, a ação conjunta com as escolas, seriam condições imperiosas para que a população local se sentisse parte do novo museu. Uma rede de docentes caxienses foi contatada e um repertório de oficinas, sugestões de temas para exposições e cursos de capacitação, foi elaborado. O diálogo com a comunidade escolar viria a se tornar uma das principais marcas do $\mathrm{MCV}$, e esteve presente desde o período inicial.

\footnotetext{
Desde a concepção inicial do Museu Ciência e Vida, o apoio ao professor sempre esteve presente, marcado inclusive em sua missão. Desta forma, o desenvolvimento da programação do Museu teve um olhar especial para esse público, não deixando, todavia de contemplar o público mais amplo. A viabilização de uma programação dinâmica e variada foi possível através de parcerias com outros museus de ciência [...] especialmente o Museu da Vida - Fundação Oswaldo Cruz e o Museu de Astronomia e Ciências Afins - MAST. (Dahmouche, Pinto e Coutinho, 2018, p.532)
}

Ao promover a articulação entre museu e escola, a instituição alcançou não apenas o público escolar propriamente, como também o público espontâneo, composto pelas famílias,e amigos, de professores e alunos que passaram a visitar o MCV, inclusive em fins de semana. Ao propor o museu como um local de aprendizado, dialogismo, lazer e convivência, estabeleceu, gradativamente, condições favoráveis à construção do hábito de frequentar espaços museais de forma geral. Esta é uma importante conquista que está muito além dos números, que desde a inauguração atingiu a marca de mais de 245.000 visitantes, pois a democratização do conhecimento não depende apenas da garantia de acesso aos equipamentos culturais, mas, também, de torná-los espaços nos quais o visitante possa se reconhecer, e, ao mesmo tempo, se reinventar.

A gratuidade e a localização central dentro do município de Duque de Caxias são quesitos fundamentais para explicar a visitação expressiva ao MCV, mas é, especialmente, a aproximação com a comunidade da região que fortalece a relação de pertencimento entre população e museu, e, por conseguinte, favorece o costume de frequentá-lo, criando hábito que poderá se estender a outras instituições similares. Em região com reduzida oferta de lazer cultural, o MCV tem se lançado na integração entre diferentes campos do saber para consolidar os laços com a comunidade local. Nessa perspectiva, apesar de não possuir, ainda, programação teatral permanente na grade de atividades, o MCV vem desenvolvendo práticas diversificadas. São oficinas, visitas teatralizadas e espetáculos que exploram a associação entre teatro e ciência visando estimular visões mais democráticas, plurais e sensíveis. "Teatro e Museu, enquanto criações do gênero humano, assumem-se igualmente como lugares privilegiados de comunicação e educação" (Costa, 2005, p.6). 
A concepção de esquete sobre Albert Einstein, seguido de atividade explorando conteúdos de Física, está entre as primeiras ações. Buscando apresentar aos estudantes a vida do cientista e estimular o gosto pelas ciências, o esquete foi apresentado em atuação itinerante, juntamente com exposição de experimentos científicos e interativos, antes mesmo da implantação plena do MCV, em 2010. A iniciativa não envolveu profissionais de artes, e sim estagiários da área de ciências que desenvolviam atividades de teatro amador. Contudo, a ação foi acolhida pela instituição por ir ao encontro sua missão maior que é a de democratizar conhecimento.

Dois anos depois, professores que vinham demonstrando claramente adesão à educação não formal como complemento à prática pedagógica, através da participação em diversas atividades promovidas pelo MCV, foram convidados a integrar a "I Mostra de Teatro \& Ciência: Sustentabilidade em cena". ${ }^{7}$, que foi apresentada em 16 de junho de 2012, no Museu.

“[...] o evento reuniu duas escolas, seis professores, 43 alunos e obteve público de 72 espectadores. A mostra foi composta pela apresentação de duas peças de teatro elaboradas pelos referidos professores em parceria com seus alunos, seguidas de debate com o público. O evento foi organizado por equipe que incluiu profissionais das áreas de Pedagogia, Ciências e Artes. [...]. Três oficinas precederam a apresentação das peças. O propósito dos encontros prévios foi a capacitação dos professores no âmbito de técnicas teatrais aplicadas ao contexto escolar, bem como ao campo dos conteúdos acerca do tema sustentabilidade". (Gardair, Dahmouche e Santos, 2017, p.1)

Entre a segunda e terceira oficinas, os professores foram orientados a multiplicar e adaptar os jogos realizados ao longo dos encontros em suas respectivas escolas, ajustando as dinâmicas ao temperamento dos estudantes, perfil das instituições e objetivos específicos a serem alcançados. Destaca-se que a principal orientação foi a de que os exercícios fossem desenvolvidos como mote para a discussão sobre sustentabilidade relacionada à prática pedagógica, realizada em sala de aula. Até a realização da mostra, uma sequência de ações foi planejada, conforme demonstramos no quadro 1:

\begin{tabular}{|c|c|}
\hline Oficina I & $\begin{array}{c}\text { Apresentação da proposta e dos participantes envolvidos. } \\
\text { Exibição e vídeos e discussão acerca do tema sustentabilidade, em consonância } \\
\text { com Gadotti (2008). } \\
\text { Debate sobre o tema com profissionais de diferentes áreas. }\end{array}$ \\
\hline Oficina II & $\begin{array}{l}\text { Desenvolvimento de exercícios de integração. } \\
\text { Realização de jogos teatrais, baseados, e adaptados, principalmente, nas } \\
\text { abordagens de Ryngaert (2009) e Spolin (2007). } \\
\text { Discussão sobre a articulação entre os jogos realizados e temas científicos. }\end{array}$ \\
\hline $\begin{array}{l}\text { Entre as of } \\
\text { e suas resp }\end{array}$ & $\begin{array}{l}\text { Il e III transcorreu espaço de dois meses. Durante este periodo, os professores } \\
\text { s turmas compuseram, na escola,peças teatrais explorando temas e dinâmicas } \\
\text { dadas nas referidas oficinas, que viriam a ser apresentado no } \mathrm{MCV} \text {. }\end{array}$ \\
\hline
\end{tabular}

7 Detalhes sobre o evento podem ser acessados no resumo estendido "Sustentabilidade em cena: uma proposta de capacitação de professores para a discussão sobre ciências e teatro", referenciado ao fim do presente artigo. 


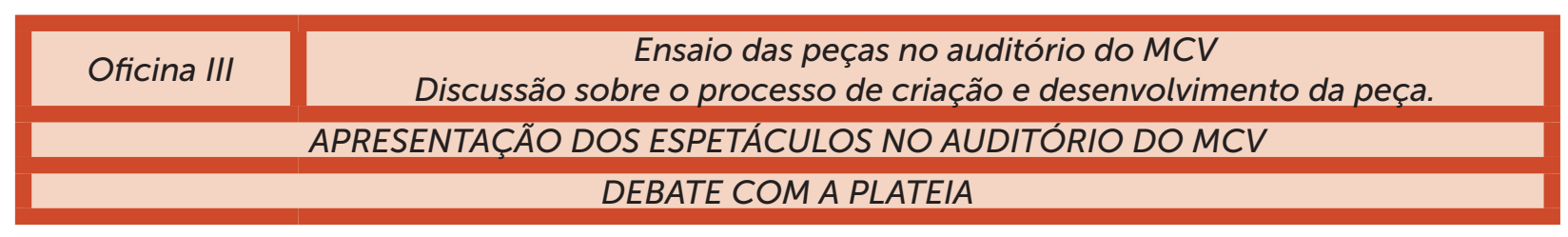

Quadro 1 - Sequência de ações para realização da Mostra Sustentabilidade em Cena

Além das oficinas presenciais, durante todo o processo houve comunicação, via correio eletrônico, entre a equipe organizadora da mostra e os participantes, no intuito de esclarecer aspectos relativos à sustentabilidade, bem como dirimir eventuais dúvidas sobre a criação das peças, texto, cenário, trilha sonora, ou mesmo atualizar as etapas realizadas na escola, como podemos verificar na transcrição de trechos de mensagens trocadas com os professores participantes:

As crianças estão surpreendendo, estão animadas e ensaiando com afinco e dedicação.Já avançamos bastante. Os alunos já conseguem fazer a cena $1 / 2$ e 3 sem interrupções, o que é muito bom, e estão percebendo a verdadeira temática da peça com a integração da música e do vídeo [...] os encontros nos ajudaram a decidir que foco abordar o tema sustentabilidade de forma a impactar os alunos positivamente e dando as crianças uma visão holística para o futuro. ${ }^{8}$

Neste canal de comunicação estabelecido também houve espaço para críticas e sugestões, como foi possível identificar em mensagem de outra professora: "Nesse projeto do teatro no museu os alunos, participantes principalmente, deveriam ter uma oficina ou uma reunião com a equipe do museu, paralela às atividades que estamos fazendo na escola." 9

O conjunto das oficinas constou de rodas dialógicas sobre conteúdos específicos ligados ao tema sustentabilidadee exercícios práticos,baseados, principalmente, nas abordagensde Viola Spolin (2007), relacionado técnicas e jogos teatrais aplicadas ao contexto escolar, e de Jean Pierre-Ryngaert, ao explorar improvisações nas quais jogar/assistir constituísse um "binômio natural" (Ryngaert, 2009, p.73). Buscou-se proporcionar aos integrantes das oficinas os papeis de ator e espectador das improvisações realizadas. Dessa forma foi possível debater os conteúdos abordados e a própria linguagem teatral das cenas realizadas e/ou assistidas pelo conjunto dos participantes. Acredita-se que, assim, a ampliação dos repertórios artísticos e científicos é facilitada.

Cabe destacar importante ponto de tensão no campo do teatro associado à divulgação científica: a relação entre forma/estética e conteúdos. A ideia de que as peças de teatro, ou atividades baseadas em técnicas e jogos teatrais, devem despertar questões não apenas sobre ciências, mas também sobre o próprio teatro, precisa ser consolidada e passa longe de ser consenso. Embora, pouco a pouco, nova mentalidade venha sendo construída, ainda é frequente a visão utilitarista, e equivocada, de que na associação à divulgação científica, o teatro seria mero instrumento a serviço das ciências. Tal compreensão deve ser eliminada, pois deturpa e apequena ambos.

\footnotetext{
8 E-mail enviado por Indiara Martins, professora participante, em 4 de maio de 2012.

9 E-mail enviado por Angela Accioly, professora participante, em 6 de maio de 2012.
} 
O teatro é muito mais que instrumento, a ciência vai além de um conjunto de conteúdos. São formas de ver, registrar e expressar o mundo. Por outras palavras: trata-se de pontos de vista e não devem ser hierarquizados.

Considerando este cenário, em consonância com Desgranges ao argumentar que "a aquisição da linguagem teatral capacita o espectador a interpretar a obra" (Desgranges, 2010, p. 172), buscamos ressaltar junto aos participantes da oficina a relevância de identificar e compreender os signos teatrais e a potência comunicativa do teatro. Procuramos evidenciar ao longo da dinâmica dos encontros, a concepção de que quanto mais se souber sobre teatro, mais se compreenderá a partir dele, independentemente das tramas a serem apresentadas. $O$ teatro traz em si uma vocação pedagógica. Aquele que "ouve histórias sendo estimulado a compreendê-las, exercita também a capacidade de criar e contar histórias" (Desgranges, 2006, p. 23).

A esta capacidade pode seguir-se a motivação para fazer história, tornando o espectador sujeito da ação. A linguagem teatral, tão rica em elementos e significados, desafia o público a interpretar os tantos signos que compõem o discurso cênico. O extenso alfabeto do teatro, composto de palavras, gestos, cenário, figurino, dentre outros, tende a ampliar as possibilidades de elaboração de diferentes leituras de mundo. (Gardair, 2012, p.24)

Seja por intermédio das rodas de conversa, ou dos jogos improvisacionais, salientamos que "tal qual a Ciência, a Arte é forma de ver, antever e inscrever" (Lopes, 2018, p.9) e que por meio da leitura ou encenação de trechos de peças teatrais, "é possível apresentar conteúdos de maneira atrativa" (Gardair, Schall, 2009, p.709) e explorar conteúdos específicos e noções importantes para a compreensão de diferentes disciplinas.

Destacamos também a importância das rodas de conversa como complementação aos jogos e improvisações e forma de envolver e integrar os participantes. Para Maturana, "a palavra conversa vem da união de duas raízes latinas, 'cum', que significa 'com', e 'versare', que significa 'dar voltas', de maneira que conversar, em sua origem, significa 'dar voltas com' outro" (Maturana, 1998, p. 80). No conjunto de ações das oficinas, a roda dialógica visou, também, entrelaçar emoção e razão no processo de linguagem.

No que se refere aos conteúdos científicos, adotou-se o entendimento de que "sustentabilidade é equilíbrio dinâmico com o outro e com o meio ambiente, é harmonia entre os diferentes" (Gadotti, 2008, p.75). Procuramos explorar a concepção de que construir um mundo sustentável implica em ações que não podem estar restritas à manutenção da saúde física do planeta, mas devem envolver a compreensão das diferenças, a busca pela justiça social e a inclusão de valores humanistas e artísticos. Manter o planeta equilibrado está ligado, necessariamente, à redução das desigualdades. Assim sendo, para tanto, é necessário abarcar múltiplos âmbitos.

A compreensão de que a preservação do ambiente, e o consequente uso cuidadoso e parcimonioso de seus recursos, dependem de transformação de comportamentos, deixa claro que não se pode desvinculá-la dos universos, social e cultural. Asseverar a integridade física dos biomas e a diversidade biológica está, portanto, e inevitavelmente, ligada à construção de uma consciência cidadã, pois implica mudança de hábitos arraigados. (Lopes, Dahmouche, Pinto, Coutinho, 2019, p. 58) 
Acerca da abordagem pedagógica, buscou-se diálogo com o ideário de Paulo Freire no que se relaciona ànoção de que todos os saberes, em diferentes complexidades e características, devem ser levados em consideração nos processos educativos, que "[...] não há seres educados e não educados. Estamos todos nos educando. Existem graus de educação, mas estes não são absolutos" (Freire, 2011, p. 14), e são transformáveis.

Em termos práticos, o entrelaçamento entre os jogos realizados e temas científicos se deu, também, a partir do caderno "Arte, Ciência e Saúde na escola", publicação cujo objetivo é "oferecer um cardápio de atividades que poderão ser adaptadas a objetivos específicos dos professores e ao perfil das turmas" (Lopes, 2007, p.6). A culminância do evento foi a apresentação de duas peças no auditório do museu: $E$ agora ou agora e Um sonho sustentável. Os espetáculos, produzidos e encenados pelos estudantes, demonstraram envolvimento dos alunos com a temática do evento, que foi enfocada de maneira a explorar as relações afetivas entre os personagens, não se restringindo à ideia de resguardar fisicamente o planeta. Em É agora ou agora, Pedro é um menino que viaja no tempo e chega até o ano de 2054. Lá, encontra os irmãos Leonardo e Catatau, donos de uma fábrica que polui o ambiente. O garoto se une a "Barbárvore", uma antiga árvore, e, juntos, buscam maneiras de tornar o planeta mais saudável.

Na trama de Um sonho sustentável, em uma pequena cidade chamada "mini-lixo", só há uma praça com velho chafariz. O lixo está por toda parte e já não existe alegria de viver. O menino Eduardo, um dos raros habitantes que ainda se preocupa com o planeta, encontra um velho cientista. Os dois tornam-se amigos e, juntos, constroem uma solução para fazer da cidade um lugar melhor para viver. Após as apresentações foi realizado debate com a plateia, em que o processo de montagem das cenas e questões relativas à reciclagem de lixo e aspectos sociais envolvidos na busca de um planeta sustentável foram discutidos.

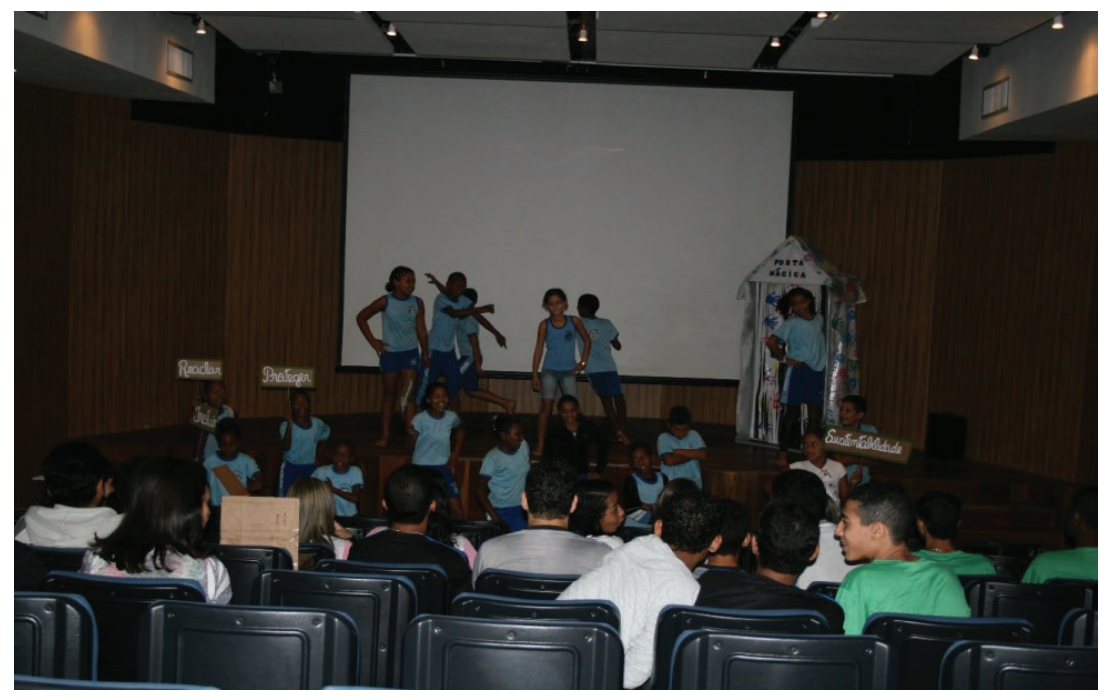

Figura 1: Cena de Um sonho sustentável. Auditório do Museu Ciência e Vida. 2012. Foto: Thelma Lopes 


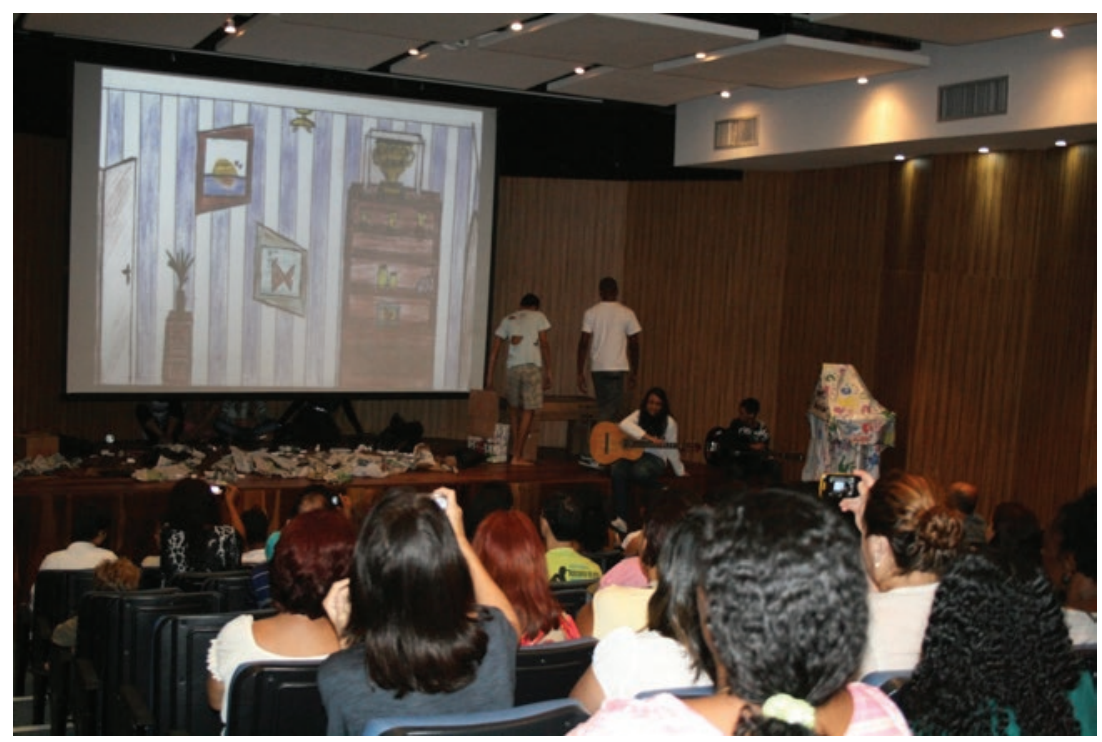

Figura 2: Cena de É agora ou agora. Auditório do Museu Ciência e Vida. 2012. Foto: Thelma Lopes

Entre 2014 e 2015, mais duas ações no âmbito da linguagem teatral foram realizadas. Na apresentação da comédia Rossum e Asimov, dois palhaços encenavam em meio a um cenário de laboratório, sobre invenção que prometia mudar os rumos da humanidade. O objetivo foi estimular a discussão acerca da tecnologia e robótica junto ao público visitante. Na visita teatralizada à exposição "A herança da Terra: salvar o planeta do Pequeno Príncipe", cujo tema principal foi o conceito de sustentabilidade a partir da ótica do autor Antoine de Saint-Exupéry, um ator representado o escritor recitava cartas e trechos de seus livros por entre os painéis expositivos, estimulando o diálogo com o público visitante.

Até o momento, o MCV não possui infraestrutura ideal para concepção de espetáculos teatrais com acabamento profissional, tampouco para a manutenção de temporadas regulares. Contudo, o MCV tem se dedicado ao estudo de possibilidades para implementação de atividades que fortaleçam a linguagem teatral integrada à divulgação científica como processo de construção de conhecimento. Nesta direção, foi programado para 2019 a realização da "Il Mostra de Teatro \& Ciência", cujo tema foi "mulheres na ciência". O evento foi planejado nos moldes da primeira edição, em 2012. Contudo não houve inscrições suficientes para a concretização da atividade.

O caso ressalta a importância de refletir sobre o quanto ainda é preciso caminhar no sentido de estreitar os vínculos da população local com as ações que exploram as artes. Por um lado, é necessário reavaliar a proposta em si e desenvolver mecanismos para averiguar os motivos pelos quais houve pouco interesse pela II mostra. Por outro, entende-se que a reação se insere em um contexto maior, no qual a desvalorização das artes é crescente e se traduz em atos concretos. Em 2018, quarenta anos após a profissão de artista ser regulamentada no Brasil, o Supremo Tribunal Federal, por exemplo, questionou a obrigatoriedade do registro profissional para o exercício de profissões voltadas ao ramo de espetáculos e diversões, gerando indignação justificada por parte da classe artística.

Em um país onde as necessidades básicas não são atendidas, como educação e saúde, cabe questionar como os possíveis papéis das artes são vistos pela sociedade 
como um todo? Embora as artes encerrem um fim em si mesmo, é sintomático que a questão ainda faça sentido. No cenário atual, não há como se esquivar do debate. Fato é que não se pode perder de vista que nem tudo que é essencial, e urgente, é mensurável ou imediatamente tangível. E quanto mais as artes são vistas como dispensáveis ou desprovidas de razão de ser, mais necessárias são.

O mundo atual parece viver um ciclo que nos retrocede à barbárie. O avanço de candidaturas radicais, a intolerância, o maniqueísmo, a incapacidade de escuta, os discursos irascíveis vêm se fortalecendo vertiginosamente, impedindo o diálogo franco, aberto e equilibrado - sem o qual, sabemos, é impossível encontrar alternativas e soluções para uma sociedade mais justa. Uma sociedade em que as diferenças e pluralidades sejam valorizadas e as desigualdades minimizadas. Portanto, em tempos nos quais, especialmente no Brasil, reina uma polaridade raivosa e perigosa de ideias e ações, a Arte, mais que nunca, é gênero de primeira necessidade. (Lopes, 2018a, p.9)

\section{Para refletir e resistir...}

Ao nos debruçarmos sobre a realidade da América Latina, em meio à produção cultural tão vasta, rica e plural, saltam aos olhos controvérsias, crises geopolíticas, dilemas, e, principalmente, desigualdades. Em grande parte formada, por países que foram transformados em colônias de exploração por nações europeias latinas, esta América traz em sua gênese a espoliação e o desequilíbrio social. A repercussão de apropriação tão deformada ecoa até os dias de hoje, de diferentes modos, e possui raízes profundas.

A expansão marítima europeia trouxe às terras americanas homens que não possuíam a intenção de se fixar nas áreas a serem ocupadas, e, portanto, não se empenhariam em criar condições favoráveis perenes para avida confortável e autônoma daqueles que habitavam na Colônia. Os interesses da Coroa postos acima de tudo, ralentaram, ou mesmo impediram, o avanço de iniciativas ligadas à produção do conhecimento. Os índices diminutos de letramento da população, a proibição de publicação de livros, e a inexistência da imprensa, constituem alguns aspectos que caracterizam o ambiente pouco propício à construção e difusão de conteúdos. $O$ panorama só viria a ser mudado, muito paulatinamente, a partir de fins do século XIX, com a chegada da Corte ao Brasil e abertura dos portos.

Em termos históricos, pouco tempo se passou entre a época quando os negros eram açoitados e os dias de hoje, mas as consequências nefastas de uma das mais profundas máculas de nosso país, a escravidão, se estende por centenas de anos e extrapolou os limites desde sempre. Não por acaso, em pleno século XXI, a população carcerária e as classes menos abastadas são compostas majoritariamente por negros. $E$ mais um indicativo de vivemos tempos sombrios é a tentativa de apagar um passado tão cruel e o ataque gratuito e infundado às políticas afirmativas, seja por parte da população ou de gestores.

Não se trata de escolher um lado. As artes, mais que as Ciências, ou mesmo a Filosofia, demonstram a coexistência de múltiplos pontos de vista. Muito além da formação acadêmica, escolha profissional ou posição político-partidária, sensibilidade e bom senso podem descortinar um mundo injusto, no qual muitos possuem pouco 
e poucos têm muito. Não há equilíbrio de oportunidades. É, portanto, um mundo que precisa ser transformado. Mas como fazê-lo? Como resistir a tantos retrocessos? Como mudar uma realidade tão desigual?

Vivemos momento em que as informações são abundantes, mas, muitas vezes, são propagadas sem a devida contextualização. Assim, é preciso resistirdes envolvendo ações que estimulem as capacidades de selecionar, ponderar e estabelecer interfaces em meio à enorme gama de informações disponíveis. Identificar relações de causas e efeitos, motivações e consequências, por exemplo, são fundamentais para gerar empatia e enxergar o outro com a benevolência que gostaríamos de ser olhados. "É a faculdade de relacionar que garante a análise de diferentes pontos de vista. Sejam fatos contemporâneos ou históricos, é a relação que estabelecemos entre eles que permite a construção de leituras mais plenas" (Lopes, 2018b, p.9)

Dessa forma, as iniciativas que buscam estreitar linguagens artísticas e diferentes campos do conhecimento devem ser estimuladas, pois convidam a colocar em relação diferentes recursos, ferramentas, signos, e, principalmente, favorecem a coexistência de diferentes pontos de vista - princípio inegociável da democracia.

\section{Referências:}

ALMEIDA, Carla. FREIRE, Maira. BENTO, Luiz. JARDIM, Gabriela. RAMALHO, Marina. DAHMOUCHE, Monica. Ciência e teatro: um estudo sobre as artes cênicas como estratégia de educação e divulgação da ciência em museus Revista Ciência e Educação, Bauru, v. 24, n. 2, p. 375-393, 2018. Disponível em: http://www.scielo.br/pdf/ciedu/ v24n2/1516-7313-ciedu-24-02-0375.pdf Acesso em: 5 jul. 2019

ALMEIDA, Carla, LOPES, Thelma. Ciência em Cena: teatro no Museu da Vida / Editado por Carla Almeida e Thelma Lopes; Carla Almeida ... [et al.]. Rio de Janeiro: Museu da Vida/Casa de Oswaldo Cruz/Fiocruz, 2019.Disponível em: http://www.museudavida.fiocruz.br/images/Publicacoes_Educacao/PDFs/LivroTeatroCienciaemCena.pdf Acesso em: 10jul. 2019.

BIVAR, Antônio; PAULINI, Celso L. Histórias do Brasil para teatro. São Paulo: Novo Século, 2007.

BRECHT, Bertolt. Pequeno Organon para o Teatro. In: Estudos sobre o Teatro. Rio de Janeiro: Nova Fronteira, 1978.

BRECHT, Bertolt, Bertolt. Devemos abolir a Estética. In: O Teatro Dialético. Rio de janeiro: Civilização Brasileira, 1967.

COSTA, Marcela Tomás de Souza de Lima. Uma Análise do Contributo da Acção Teatral para a Função Educativa dos Museus da RAM. Lisboa, 2005. Dissertação (Mestrado) - Universidade Lusófona de Humanidades e Tecnologias. 
COUTINHO, Marina Henriques. O teatro aplicado em questão: abrangência, teoria e o uso do termo. Ouvirouver, Uberlândia v. 8 n. 1-2 p. 110-127 jan.-ljun. - ago-dez. 2012. Disponível em: www.seer.ufu.br/index.php/ouvirouver/article/view/12498/15485 Acesso em: 12 jul. 2019.

DAHMOUCHE, Monica Santos; PINTO, Simone Vieira; COUTINHO, Liliana. A Implantação do Museu Ciência e Vida em Duque de Caxias/RJ como uma política cultural para a baixada fluminense. In: IX Seminário Internacional de Políticas Culturais, 2018. Anais do IX Seminário Internacional de Políticas Culturais, Fundação Casa Rui Barbosa, Rio de Janeiro, p. 527- 538.

FEYERABEND, Paul Karl. A Ciência em uma sociedade livre. São Paulo: Editora Unesp, 2011.

DESGRANGES, Flávio. A Pedagogia do espectador. São Paulo: Hucitec, 2010.

DESGRANGES, Flávio. Pedagogia do Teatro: provocação e dialogismo. São Paulo: Hucitec, 2006.

FREIRE, Paulo. Pedagogia do oprimido. Rio de Janeiro: Imago, 2001.

GADOTTI, Moacir. Educar para a sustentabilidade. Revista Inclusão Social,Brasília, v. 3, n. 1, p. 75-78, out. 2007/mar. 2008. Disponível em:http://revista.ibict.br/inclusao/ article/view/1624/1830 Acesso em: 15 jun.2019

GARDAIR, Thelma Lopes. Integrando a percepção de estudantes à criação de peça teatral: uma alternativa de educação científica em diálogo com as artes. Rio de Janeiro, 2012. Tese (Doutorado) - Ensino em Biociências e Saúde, Fundação Oswaldo Cruz. Disponível em: https://www.arca.fiocruz.br/bitstream/icict/6957/1/DO\%202008\%20 -\%20Thelma\%20Lopes\%20Carlos\%20Gardair.pdf? Acesso em: 11 nov. 2019.

GARDAIR, Thelma Lopes, SCHALL, Virgínia Torres. Ciências possíveis em Machado de Assis: teatro e ciência na educação científica. Revista Ciência e Educação, Bauru, vol. 15, n. 3, Bauru, 2009. Disponível em: http://www.scielo.br/scielo.php?pi$\mathrm{d}=$ S1516-73132009000300015\&script=sci_arttext. Acesso em: 2 jun.2019

GARDAIR, Thelma Lopes, DAHMOUCHE, Monica, SANTOS, Luana Balbino. Sustentabilidade em cena: uma proposta de capacitação de professores para a discussão sobre ciências e teatro. Canal CECIERJ. Rio de Janeiro, Fundação Cecierj, jun. 2017. Disponível em: https://canal.cecierj.edu.br/recurso/16847 Acesso em: 12 nov.2019

JAMESON, Frederic. O Método Brecht. Rio de Janeiro: Vozes, 1999.

KOYRÉ, A. Estudos da história do pensamento científico. Rio de Janeiro: Forense Uni- 
versitária, 1991.

LATOUR, B. A esperança de Pandora. Estudos sobre a realidade dos estudos científicos.Bauru, São Paulo: EDUSC, 2001.

LOPES, Thelma. Arte e ciência: ligações necessárias. Jornal do Brasil, Rio de Janeiro, 10 mai.2018, p.9.

LOPES, Thelma. Triste risco de retrocesso à barbárie. Jornal do Brasil, Rio de Janeiro, 24 abr. 2018a, p.9.

LOPES, Thelma. Shakespeare, Pasteur e a importância de contextualizar. Jornal do Brasil, Rio de Janeiro,19ago. 2018a, p.9.

LOPES, Thelma. Arte, Ciência e saúde na escola: caderno de atividades. Rio de Janeiro: Museu da Vida/ Casa de Oswaldo Cruz / Fiocruz, 2007.

LOPES. O palco de Brecht e o céu de Galileu, tudo se move. In: Ciência e arte. Imaginário e descoberta. Matos, C. (org.) São Paulo: Terceira Margem, 2003.

LOPES, Thelma. O palco de Brecht e o céu de Galileu: tudo se move. Teatro e Ciência nas três versões dramáticas de Bertolt Brecht. 2000. Dissertação (Mestrado) - Centro de Letras e Artes. Universidade Federal do Estado do Rio de Janeiro. Rio de Janeiro, 2000.

LOPES, Thelma. DAHMOUCHE, Monica Santos, PINTO, Simone Vieira; COUTINHO, Liliana.A divulgação científica e o mundo sustentável: o "Museu Ciência e Vida". In: Hacia La sostenibilidaden América Latina: aportes desde ladivulgación de laciencia / compiladora Margoth Mena-Young; San José, Costa Rica: Universidad de Costa Rica, Vicerrectoría de Investigación, Centro de InvestigaciónenComunicación, 2019. 200 p. Disponível em:http://cicom.eccc.ucr.ac.cr/wp-content/uploads/2019/06/ Hacia-la-sostenibilidad-en-Ame\%CC\%81rica-Latina-CicomUCR-RedPOP-UNESCO-2019.pdf?fbclid=IwAR10Mh9_O4cUBje4Ax5oeEYg7MwifxjfH5U7OXODxxdPOgAR9yOn1M6_ZqM. Acesso em: 12 jul. 2019.

MASSOLA, Gustavo Martineli; CROCHIK, José Leon; SVARTMAN, Bernardo Parodi. Por uma crítica da divulgação científica. Psicol. USP, São Paulo, v. 26, n. 3, p. 310315, Dec. 2015. Disponível em: http://www.scielo.br/pdf/pusp/v26n3/1678-5177pusp-26-03-00310.pdf Acesso em: 23 jul. 2019.

MATURANA, Humberto. Emoções e linguagem na educação e na política. Belo Horizonte: UFMG, 1998.

MOREIRA, Leonardo, MARANDINO, Martha. O teatro em museus e centros de ciên- 
cias no Brasil. História, Ciências, Saúde - Manguinhos, Rio de Janeiro, v.22, supl., dez. 2015, p.1735-1748. Disponível em:http://www.scielo.br/pdf/hcsm/v22s0/ 0104-5970-hcsm-22-s1-1735.pdf.Acesso em: 20 mai.2019.

ROOT-BERNSTEIN, Bob; SILER, Todd; BROWN, Adam; SNELSON, Kenneth. ArtScience: Integrative Collaboration to Create a Sustainable Future. Leonardo, v.44, n.3, pp. 192, 2011.

RYNGAERT, Jean-Pierre. Jogar, representar: práticas dramáticas e formação. São Paulo: Cosac Naify, 2009.

SOUZA, Daniel; PORTO, Marta (Org.). Aids e teatro: 15 dramaturgias de prevenção. Rio de Janeiro: Editora Senac Rio, 2004.

SPOLIN, Viola. Jogos teatrais na sala e aula: o livro do professor. São Paulo: Perspectiva, 2007. 